\title{
A Survey of EFL Learners' Attitudes toward Information and Communication Technologies
}

\author{
Junhong Liu \\ Yangquan College, Taiyuan University of Technology, 045000, China \\ E-mail: Chinajune225@Yahoo.com.cn
}

\begin{abstract}
In response to the widespread use of and ever-changing nature of Information and Communication Technologies (ICT), various investigations were carried out regarding attitudes toward ICT. This paper attempted to investigate college non-English majors' attitudes toward the integration of Information and Communication Technologies into English learning and factors contributing to their attitudes so as to provide some constructive information and suggestions for the adoption of technology in foreign language education.
\end{abstract}

Keywords: Attitude, Information and Communication Technologies (ICT), Attitude toward ICT

\section{The Increasingly Important Role of Technology in College English Education}

Technology has an important position in our society, affecting our life more and more. A worldwide increase in the demand for foreign language instruction and learning has stimulated interest in how technology can help meet students' need. The use of technology in teaching foreign language has been increasing dramatically over recent decades as the merits of technology in language learning and teaching are becoming more widely acknowledged worldwide.

Teaching and learning foreign language through technology has become a new trend in foreign language education all over the world. Technology is playing a greater role during class and home study, as computer-assisted instruction and interactive media technologies supplement the traditional use of the chalk and the blackboard.

The increasing connection between English and technology creates new demands for College English education (Zhang, 2003). In China English is taught as a foreign language as a compulsory course for all the undergraduates who do not major in English. However, the English literacy of the college students have generally been seen as unsatisfactory although most of them have learned English for over 6 years, and the approach to teaching English has been seen as ineffective, far from satisfying social needs (Dai, 2001a, 2001b). Under the circumstances, the Ministry of Education has launched the campaign of College English reform ever since 1996 and determined afterwards to take three steps to reform the current situation of College English teaching. The first step is to apply advanced information technology to college English teaching and learning on a wide basis in order to further the computer-based College English reform) (Liu, 2003). In January 2004 the Ministry of Education issued new college English teaching requirements and proposed hypertextualization as one of the four goals in the new round of College English reform (Hu, 2004). The potential benefits of ICT use in college English education being recognized by the authorities at all levels, increasing funds has been spent recently on language labs, computer multimedia equipments, wireless network on campus to meet administrative and teaching purposes to improve the situation throughout the country.

Woodrow (1987) points out that integrating technology into the educational curriculum has the potential to change the process of education drastically. He also suggests that any successful change in educational practice necessitates the development of positive user attitudes toward the new technology. From a review of literature of the kernel academic journals published in China from 2000-2007, it is noticed that some educators advocate that interaction between teacher and students in the English class is so important that no technology can take the place of it. They propose that instruction using ICT should be viewed as an enhancement to the traditional way of teaching rather than a substitute for it (Zhou, 2003; Shi, 2003). A number of studies have explored the use of technology in language learning and teaching (Li, Li, Zhong, Xiong, Liu, 2006), but very few focus on learners' attitudes toward the integration of technology into English teaching and learning. Therefore, the purposes of the study are to examine the college students' attitudes toward information and communication technologies in English teaching and learning and to identify and analyze possible factors that account for the college students' attitudes toward ICT and ICT adoption in their English learning. As an English teacher, the researcher also attempt to find out the role CET 4 has played in accounting for college students' attitudes toward ICT in their English learning.

\section{Studies on Factors Affecting Learners' Attitudes toward ICT}

2.1 Attitudes toward ICT

Attitudes are an evaluative reaction to some referent or attitude object, inferred on the basis of the individual's beliefs or 
opinions about the referent (Gardner, 1985). Attitudes have generally been divided into three components: affect, cognition, and behavior (Zimbardo,1969). The affective component consists of "a person's evaluation of, liking of, or emotional response to some object or person". The cognitive component has been conceptualized as "a person's beliefs about, or factual knowledge of, the object or person". The behavioral component involves "the person's overt behavior directed toward the object or person".

The three-fold definition is significant in that it provides us with ideas about how to measure them. The affective component could be measured by physiological responses or verbal statements of like and dislike, while the cognitive component might be measured by self-ratings of beliefs or by the amount of knowledge which a person has about some topic. The behavioral component could be measured by observation of how the person behaves in specific stimulus situations.

Following the above definitions, in the present study, students' attitudes toward ICT consist of students' feelings toward ICT (affective), students' belief and factual knowledge of ICT (cognitive) and students' behavioral intentions and actions with respect to ICT (behavioral). The operational definition of "attitudes toward ICT" in this study is students' knowledge, belief, liking and intent for future use of ICT.

\subsection{Factors Affecting learners' Attitudes toward ICT}

To identify possible influencing factors on computer attitudes, the literature review could not be confined to the Chinese studies. Studies from other countries have also been used, provided it could be assumed that the identified influencing factors are relevant in the Chinese context as well.

Rogers (2003) asserts that one of the major factors affecting individual's attitudes toward innovation is the attributes of the technology. In order to address the "innovation" differences, he identified five perceived attributes of innovations: 1) relative advantage, 2) compatibility, 3) complexity, 4) trialability and 5) observability. Therefore, a new technology will be increasingly diffused if the adopters perceive that the innovation has an advantage over previous innovations, is in agreement with existing practices, not complex to understand and adopt, shows observable results and can be experimented with on a limited basis before adoption. In a study of EFL teachers' attitudes toward ICT, Albirini (2006) noted that participants' perception of ICT attributes was the largest factor in predicting their attitudes toward ICT. Zhang Qi (2007) found in her study that EFL teachers' perception of ICT attributes, i.e. relative advantage, compatibility, simplicity, and observability, explained the major difference in teachers' attitudes toward ICT and ICT use. Her study adds to the theoretical accountability of Rogers' (2003) innovation diffusion theory in the field of ICT adoption and implementation.

In this study ICT attributes are defined as the "advantage", "compatibility", "simplicity" and "observability" of Information and Communication Technologies (ICT) as perceived by the college students. Trialability is left out from the present study because students in the study do not have the chance to experiment with the computers before the installation in the classrooms.

Cultural perception is also an important factor in predicting students' adoption of ICT in English learning. Rogers (1995, as cited in Albirini 2006) and Thomas (1987, as cited in Albirini 2006) emphasize the importance of the cultural or social norms of a given country to the acceptance technology among its people. Rogers (2003) indicates that system norm was an important predictor of diffusion of innovations. He defines "norms" as "the established behavior patterns for the members of a social system". It is therefore supposed that norms can become barriers to the adoption of innovation, as the norms of a society or an organization usually tell people what they are expected to do in a given culture.

As ICT have originated and developed in developed countries, its implementation in developing countries may encounter resistance because of teachers' and students' perceptions of its influences on the nation and the school they are in. In this study, cultural perceptions of ICT mean the college students' perceptions of value, relevance and impact of ICT as it relates to Chinese society and colleges as well.

Besides Perceived ICT Attributes and Cultural Perceptions of ICT, previous researches show factors that have been associated with computer attitudes are Gender Difference, Social Environment, Computer Experience, ICT Competence and Self-confidence about Use, Access to Internet

In this study, students' attitudes will be examined to explore in what ways ICT is beneficial and helpful in the process of foreign language learning, while at the same time the cultural implication of application of ICT into English teaching and learning will be investigated to account for their attitudes toward it. Students' ICT competence, ICT confidence, ICT attributes, cultural perceptions of ICT, together with students' personal characteristics will be examined to see if they are correlated with students' attitudes toward ICT.

\subsection{Objectives of the Present Study}

In general, this study is designed to find out college EFL learners' attitudes toward ICT and ICT adoption in their 
English learning. It also attempts to explore the factors contributing to the differences in students' attitudes. To be specific, the following questions will be explored:

Quantitative Study:

(1). What are the subjects' attitudes toward ICT as a medium for learning English?

(2). What are the subjects' perception of the major factors contributing to their attitudes toward ICT a). ICT attributes? b). Cultural relevance of ICT to the Chinese society and colleges? c). Their level of ICT competence? d). Their level of ICT confidence? e). Their level of using ICT to learn English?

(3). Do the extraneous variables (gender, major and home location) significantly correlate with subjects' attitudes toward ICT?

(4). Are there any association between the subjects' ICT attitudes and learning outcomes, in terms of ranks in CET4?

Qualitative Study:

(5). What are the possible factors accounting for the subjects' positive attitudes toward ICT and facilitating their adoption of ICT in English learning and what lies behind the subjects' negative attitudes toward ICT and inhibits them from adopting ICT in English learning?

\section{Research Method}

The participants for this study were 140 third -year non-English majors out of the approximately 7000 population at Yangquan College, Taiyuan University of Technology. When selecting students, an attempt was made to include approximately equal numbers of male and female students from different majors to allow the researcher to have a balanced sample to make comparisons related to gender issues. The selected classes were four of sciences \& engineering consisting of 70 students, and three of social sciences made up of 70 students as well. Instruments for this study were questionnaires and a focus group interview. Most items in the questionnaire in the quantitative study were developed based on Zhang Qi's (2007) research in English as Foreign Language teachers' attitudes toward ICT in science universities in Beijing, Albirini's (2006) research of Syrian EFL teachers' attitudes towards the adoption of ICT in high schools and Cretchley's study of computer confidence in a technology-enriched science and engineering mathematics course in an Australian university. The Cronbach's $\alpha$ reliability coeffieicents for the scales used in Albirini's research were: computer attitude (0.90), computer competence (0.94), computer attributes $(0.86)$ and cultural perceptions (0.76) and Cretchley's computer confidence scale also demonstrate consistently high Cronbach internal consistency alphas (around 0.9) and high test/re-test reliability (Cretchley, 2007). The questionnaire was first translated into Chinese from English and then revised based on Zhang Qi's study according to the Chinese higher education setting and principles of writing attitudes statements. The revised questionnaire consisted of six sections: personal information, ICT competence, attitudes toward ICT, ICT confidence, ICT attributes, and cultural perceptions. For the convenience of categorization, CET4 achievement levels, learning English using ICT and access to Internet were included in the personal information scale.

For interview, the researcher of the present study chose the form of focus group interview to make sure that the interviewees would be willing to express their feelings freely. It serves as a kind of complementary of deeper and richer data for the quantitative data obtained by questionnaires in order to offer some explanations for the results of the statistical analysis. Therefore, a checklist of open questions were prepared as a frame for discussion in the interview intended to get further information about the participants' attitudes toward ICT in their English learning.

Reliability of the instrument was examined based on the data from the pilot study through SPSS version 13.0. One item resulting in a lower reliability coefficient was deleted. The overall Cronbach's $\alpha$ reliability coefficient was 0.91 ; and the individual coefficient for the ICT competence, attitudes toward ICT, ICT confidence, ICT attributes and cultural perceptions were $0.85,0.91,0.77,0.70$ and 0.72 respectively. The survey was conducted form November 10 th to November 18th with a response rate of $97.1 \%$. On the 18th of November, 136 questionnaires were collected altogether, of which six were not analyzed because these six questionnaires were incomplete with unfinished items.

The focus group interview was performed among six participants made up of four males (two majoring in Civil Engineering and two in Law) and two females majoring in Accounting. The interview was conducted and audio-recorded in classroom 109 of Teaching Building No.1 on December 11th. The data collected from the questionnaire was analyzed via SPSS 13.0. The differences and correlations between the two groups were regarded significant if $\mathrm{p}<0.05$.

The data obtained from the focus group interview were analyzed using an interpretive approach. The audio-recording was transcribed immediately after the interview and then a categorization analysis was performed.

\section{Results and Discussion}

\subsection{Summary of Major Findings}

In response to the widespread use of and ever-changing nature of ICT, various investigations were carried out regarding 
attitudes toward ICT. This study has reported on a survey for investigating college students' attitudes toward ICT at Yangquan College, Taiyuan University of Technology. In general, college students have taken positive attitudes toward ICT and ICT integration into education although ICT are scarcely seen being used in English classrooms on a daily basis and far from being incorporated into curriculum. The study reveals that female college students adopt more favorable ICT attitudes than males and students majoring in the liberal arts are more positive than science students toward ICT. College students' perceptions of ICT attributes, that is, relative advantage, compatibility, simplicity, and observability, explain the major difference in students' attitudes toward ICT and ICT adoption. Moreover, CET4 achievement correlates with students' ICT attitudes in a positive way. Cultural perceptions of ICT, together with the impact of the social environment like the attitudes of others and ICT experience, also influence college students' attitudes to some extent.

Students in this study are fully aware of the advantages of ICT in their English learning. However, both the quantitative and qualitative study show that the complexity/simplicity of ICT negatively affects college students' attitudes toward ICT and their adoption, which is in agreement with the findings of Rogers \& Shoemaker. This discovery from the quantitative study has then been confirmed in the findings from the qualitative study, especially in terms of complexity of ICT use and consumption of time. Moreover, the participants in both the qualitative study and quantitative study have reservations about the compatibility of ICT use with the school policy and curriculum goals. Besides, CET4 achievement correlates with students' ICT attitudes in a positive way. The study shows that females have scored better than males in CET4 and display more interest, confidence in English, and therefore adopt more positive attitudes toward ICT in English learning than males. Further analyses make known that students' anxiety and negative attitudes toward English learning, arising from the problem involving improving communicative competence in a real sense and passing CET4 meanwhile as well as the difficulty in balancing the time allocating to major study and English learning, lie in low or failure CET4 marks and contribute partially to students' negative attitudes toward ICT and ICT adoption in English learning.

Warschauer (1998) states that "teachers can enhance student motivation by helping students gain knowledge and skill about using computers, giving them ample opportunity to use electronic communication, and carefully integrating computer activities into the regular structure and goals of the course". However, in this study students' attitudes are not influenced by their teachers in the English classrooms where the traditional way of instruction is prevalent although the social environment like the ICT attitudes of parents, peers and classmates have affected students' attitude toward ICT positively. For the students the deficiency in the actual use of ICT in English classrooms and lack of professional assistance from teachers in ICT use prove to be great obstacles to learning English through ICT in and outside classrooms.

Cultural perceptions of ICT are important predictors of college students' ICT attitudes in this study. The majority of the subjects agree that ICT will make a difference in our classroom, schools, or lives $(72.3 \%)$. Students in this study are aware of not only the advantages of ICT in their English learning but also the importance of ICT use for their future jobs. As far as the compatibility of ICT with our traditional culture is concerned, almost half of the participants think ICT will not increase our dependence on foreign countries and cultures, $63.9 \%$ of the subjects believe using ICT will not hinder Chinese from carrying on their tradition and $59.2 \%$ of the respondents think ICT should be a priority in education.

Technology is only a tool. Technology cannot transform teaching by itself (Armstrong and Yetter-Vassot, 1994). ICT itself cannot change the whole educational system and thus more renovations like the testing system and pedagogical change should be made. We still have a long way to go before we could integrate ICT into foreign language education in a real sense.

\subsection{Discussion}

The result of this study is in agreement with previous researches on the following factors affecting learners' ICT attitudes, i.e., perceived ICT attributes, cultural perceptions of ICT, computer experience and ICT confidence. Perceived ICT attributes predict the largest proportion of variance of students' ICT attitudes. Perceived advantages of ICT as an educational medium account for students' positive attitudes and their willingness to adoption of ICT in their English learning. However, data from the study suggest that students are less positive concerning the simplicity of ICT attributes and that respondents in this study have reservations about the compatibility of ICT use with school policy and curriculum, which is in accordance with Zhang Qi's (2007) researches on Chinese EFL teachers' ICT attitudes. This study also reveals that cultural perceptions of ICT rank the third in predicting students' attitudes toward ICT. In Zhang Qi's study, a majority of the Chinese EFL teachers were neutral about if ICT fit the national and organizational culture, while students in this study are more positive about it. A possible explanation might be that young students and their teachers tend to view new things from different perspectives. A second explanation might be that there exists a gap between EFL teachers' belief, expectation and students' real need as far as foreign language education is concerned. Data from the qualitative study show that computer experience is related to more positive attitudes toward ICT. This is 
in agreement with the findings from a survey research conducted by Chantal Bovée, Joke Voogt and Martina Meelissen (2007). They (Bovée, C. et al., 2007) have found the lower social status of the school's students, the schools' low accessibility to computer facilities, and the limited computer experience of the student might have contributed to a lower positive attitude. This is also confirmed in the finding from the quantitative study - students coming from the countryside showed more anxiety and unease about ICT than students from the city.

It has been pointed out that the social environment like the computer attitudes of parents, teachers and their encouragement of students to work with a computer have great influence on students' attitudes. However, in this study students' attitudes haven't been influenced by their teachers in the English classrooms where the traditional way of instruction still prevails although the social environment like the ICT attitudes of parents, peers and classmates have affected students' attitudes in a very positive way. The deficiency of ICT adoption by English teachers in this study serves as a good explanation for this disagreement with previous research findings.

Previous researches are generally consistent on the positive effects of computer competence on participants' attitudes toward technology use in foreign language teaching and learning. However, ICT competence in this study is found to have no significant correlation with ICT attitudes. A possible explanation is that participants in this research do not have significant difference in their knowledge of ICT. A second account may be that the instrument used in this study should be further revised to have reference to language learning rather than solely on the level of technology adoption.

The study reveals that female college students adopt more favorable attitudes toward ICT than males. This result contrasts with the previous studies on gender differences in computer attitudes which were mainly conducted in western countries showing more technophobic and less positive attitudes amongst girls compared with boys. Social and cultural expectations in western societies might explain the sex differences in attitudes, while data from this survey suggest that females perform better than males in CET4 and display more interest and confidence in English than males. Students' anxiety and negative attitudes toward English has been detected by further analyses of English achievement, which account mainly for gender differences in attitudes in this study.

It is also shown that students' attitudes in this study correlated negatively with access to Internet (rho $=-0.384)$, which is in disagreement with previous studies, and students' LEUICT (Learning English Using ICT) ( $\mathrm{rho}=-0.338, \mathrm{p}<0.01$ ). Rogers (2003) states it is one thing for an individual to decide to adopt a new idea, quite a different thing to put the innovation to use, as problems in exactly how to use the innovation crop up at the implementation stage. In this study the fact might also be related to the school environment. Students have difficulty integrating ICT well into English learning because of the deficiency in the actual use of ICT in English classrooms and lack of professional assistance from teachers in ICT use outside the English classrooms, which results in students' negative ICT attitudes to a large extent. Besides, for most of the students the only motivation to learn English is to pass English tests and CET4 so as to graduate. According to some participants learning English through ICT is not so effective as the traditional way to cope with CET4.

\subsection{Pedagogical Implications}

The results of this study lead to several implications for pedagogy and administration, as follows:

First, ICT in education is an unavoidable trend. To make the most of the benefits of ICT, policy maker should pay as much attention to the software as the hardware. That is, it's not enough to establish a good technological environment. The more important thing is to train teachers how to apply technology effectively in their domain.

Second, as educators we should not say that we should stop using technology if it does not fit. Instead, we should take an attitude that is fearless in the use of technology, ask ourselves how to conquer these disadvantages, develop full potential of technology in our instruction as students' facilitators and guide them to become lifelong learners.

Third, English instruction should not be test-oriented, instead efforts should be made to improve students' comprehensive ability in a real sense, encourage students to use ICT in and out side class, for example, ask them submit their assignments online so as to promote their motivation and interest of learning English through ICT gradually.

Fourth, in order to make the best of ICT in language teaching and learning, digital literacy should also be reflected in the testing systems (Zhang, 2003). CET4 as a test of college students' English proficiency hasn't covered all the necessary skills needed for a college student, therefore, test reform is necessary and achievements of the test shouldn't be attached too much importance in deciding whether a student will be granted a BA certificate or not. The school authority should take measures from a macro aspect of view to motivate the students by providing a more active, free learning circumstance rather than put too much pressure on students by focusing on CET4.

\section{References}

Albirini, A. (2006). Teachers' attitudes toward information and communication technologies: the case of Syrian EFL teachers. Computers \& Education 47, 373-398.

Armstrong, K. \& Yetter-Vassot C. (1994). Transforming teaching through technology. Foreign Language Annuals 27(4), 
475-86.

Bovée, Chantal, Joke Voogt and Martina Meelissen. (2007). Computer attitudes of primary and secondary students in South Africa. Computers in Human Behavior 23, 1762-1776.

Christensen, R. \& Knezek, G. (1996). Constructing the teachers' attitudes toward computers (TAC) questionnaire. ERIC Document Reproduction Service No. ED398244.

Cretchley P. (2007). Does computer confidence relate to levels of achievement in ICT-enriched learning models? Education and Information Technology 12, 29-39.

Gardner, R. C. (1985). Social psychology and second language learning: the role of attitudes and motivation. London: Edward Arnold.

Warschauer, M. (1998). Electronic Literacies: Language, culture, and power in online educa tion. Mahwah, NJ: Lawrence Erlbaum Associates.

Woodrow, J. E. (1987). Educators' attitudes and predispositions towards computers. Journal of Computers in Mathematics and Science Teaching, 27-37.

Zhang, W. (2003). Doing English digital: An assessment model for a new college English curriculum in China. Dissertation. Columbia University. UMI Number: 3088460.

Zimbardo, P. G. \& Ebbesen, E. B. (1969). Influencing Attitudes and Changing Behavior. Reading, MA: Addison-Wesley. Chen, Xiangming. (2006). Qualitative Research in Social Science. Beijing: Educational Science Publishing House.

Dai, Weidong. (2001a). Constructing the system characteristic of English teaching in China. Foreign Language Teaching and Research 5, 322-327.

Dai, Weidong. (2001b). Time-consuming low efficiency in foreign language teaching: reflection and solution. Foreign Language Teaching and Research 7, 1-32.

$\mathrm{Hu}$, Zhuanglin. (2004). Individualization collaboration modularization and hypertextualization of college English education - a discussion about the conception of TEACHING REQUIREMENTS. Foreign Language Teaching and Research 5, 345-350.

Li, Jianhua, Li, Luping, Zhong, Ling, Xiong, Jinglin and Liu, Jinghong. (2006). Reforms in online college English education. Foreign Language Teaching and Research 1, 61-65.

Liu, Runqing and Dai, Manchun. (2003). Reform of College Foreign Language Education: Present Situation and Strategies. Beijing: Foreign Language Teaching and Research Press.

Shi, Baohui. (2003). Carry out the college English teaching reform judiciously. Foreign Language and Foreign Language Teaching 5, 384-385.

Zhang, Qi. (2007). EFL Teachers' Attitudes toward Information and Communication Technologies and Attributing Factors. Dissertation. Peking University.

Zhou, Liuxi. (2003). Something can be done in public English. Foreign Language Teaching and Research 3, $224-226$. 